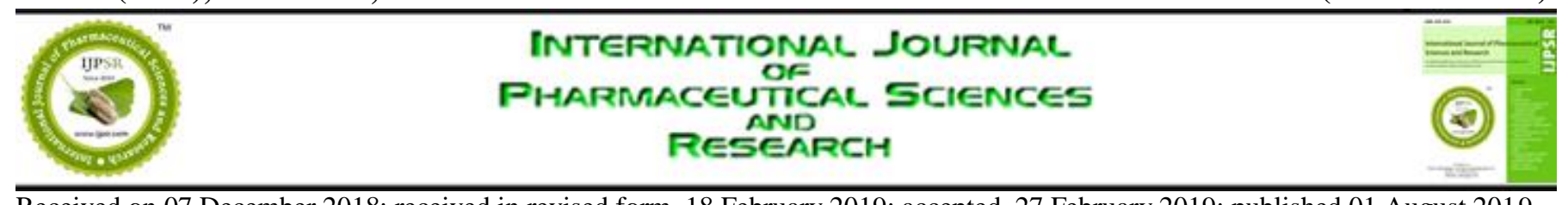

Received on 07 December 2018; received in revised form, 18 February 2019; accepted, 27 February 2019; published 01 August 2019

\title{
AN OVERVIEW OF THERAPEUTIC POTENTIAL OF THYMOQUINONE
}

\author{
Swati Agarwal ${ }^{1}$, Rashmi Srivastava ${ }^{2}$ and Neetu Mishra ${ }^{* 3}$ \\ Centre of Food Technology ${ }^{1,2}$, Department of Home Science ${ }^{3}$, University of Allahabad, Allahabad - \\ 211002, Uttar Pradesh, India.
}

Keywords:

Thymoquinone, Nigella sativa, Therapeutic potential, Anti-oxidant, Anti-microbial, Anti-inflammatory

Correspondence to Author:

Dr. Neetu Mishra

Associate Professor,

Food and Nutrition,

Department of Home Science,

University of Allahabad, Allahabad -

211002, Uttar Pradesh, India.

E-mail: neetum1976@gmail.com

\begin{abstract}
Herbal medication has attracted much attention in recent years and is being used as an alternative to chemical medicines. Some evidence supports the positive effects of medicinal plants in the prevention and treatment of different types of diseases. Thymoquinone (TQ) is the most abundant component of Nigella sativa seeds, and most of the properties of Nigella sativa are attributed primarily to TQ. It belongs to a class of naturally presenting phenols, chemically known as 2-isopropyl-5-methyl benzo-1, 4-quinone $\left(\mathrm{C}_{10} \mathrm{H}_{12} \mathrm{O}_{2}\right)$, is a dark yellow crystalline monoterpene diketone, abundantly found in the seeds of Nigella sativa. Besides Nigella sativa, TQ is an active ingredient of several plants as Juniperus, Monarda, Coridothymus, Agastache, Satureja. It has been reported to possess various beneficial therapeutic effects including anti-oxidant, anti-inflammatory, anti-microbial, antidiabetic, hepato-protective and cardioprotective effects. It is significant to say that TQ may be effective as a powerful contender of natural origin with therapeutic potential against an array of maladies.
\end{abstract}

INTRODUCTION: Thymoquinone (TQ) is a major bioactive constituent mainly found in Nigella sativa 1. Nigella sativa, belonging to Ranunculaceae family is commonly known as black cumin, Kalonji or kalajeera ${ }^{2}$. It is an annual herbaceous plant, native to south and southwest Asia. Seeds of Nigella sativa have been used for thousands of years as a spice and food preservative to a variety of food products as bread, yogurt, pickles, sauces, salads, etc. ${ }^{3}$ Furthermore, Nigella sativa seeds are reported to possess antihistaminic, antihypertensive, antimicrobial, antitumor, insect repellent and lactogogous effects ${ }^{4,5}$.

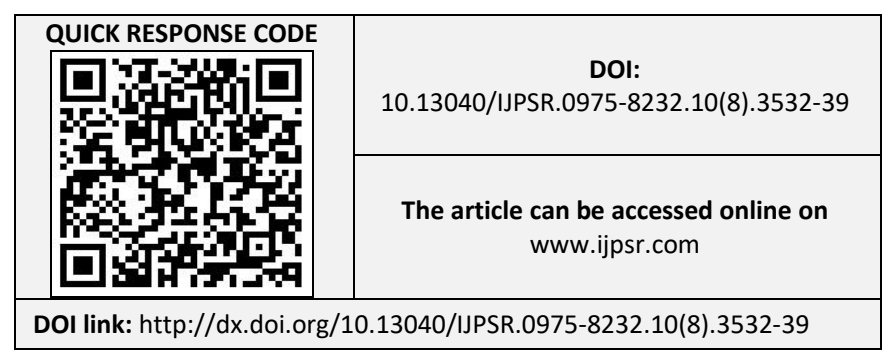

Nigella sativa seeds contain several bioactive compounds that include thymoquinone (TQ), dithymoquinone (DTQ), thymohydroquinone (THQ), thymol (THY), tocopherols, trans-retinol, and selenium etc. TQ is the most abundant phenolic compound, and this functional ingredient is predominantly present in fixed and essential oils of Nigella seeds 6 .

Besides Ranunculaceae, this compound has been confirmed its presence in several genera of the Cupressaceae and Lamiaceae family ${ }^{7}$. The traces of TQ were also reported in Nigella arvensis ${ }^{8}$. It was first extracted by El-Dakhakhny using thin layer chromatography on silica gel ${ }^{9}$. Illustration of Nigella sativa plant, its flower, seeds and the chemical structure of TQ are presented in Fig. 1. TQ holds anti-oxidant, analgesic, anti-convulsant, and anti-cancer effects. It has also been shown to protect against liver, kidney and heart damage in several animal studies. 
TQ is an important agent of natural origin and has generated interest in the field of scientific research for its therapeutic effect. The present review presents an overview of its therapeutic potential in a disease condition.

Chemistry of Thymoquinone: TQ is a monoterpene diketone, chemically known as 2isopropyl-5-methyl benzo-1, 4-quinone. It is a dark yellow crystalline substance with a boiling point and melting point of $230-232{ }^{\circ} \mathrm{C}$ and $44-45{ }^{\circ} \mathrm{C}$, respectively. Its molecular weight is 164.204 $\mathrm{g} / \mathrm{mol}$, and $\log P$ value is 2.20 . Due to low molecular weight (less than $500 \mathrm{~g} / \mathrm{mol}$ ) and $\log P$ (less than five) value, it can penetrate the bloodbrain barrier. Thus, it might be suitable for clinical trials ${ }^{10,11}$. The most significant properties are summarized in Table 1.
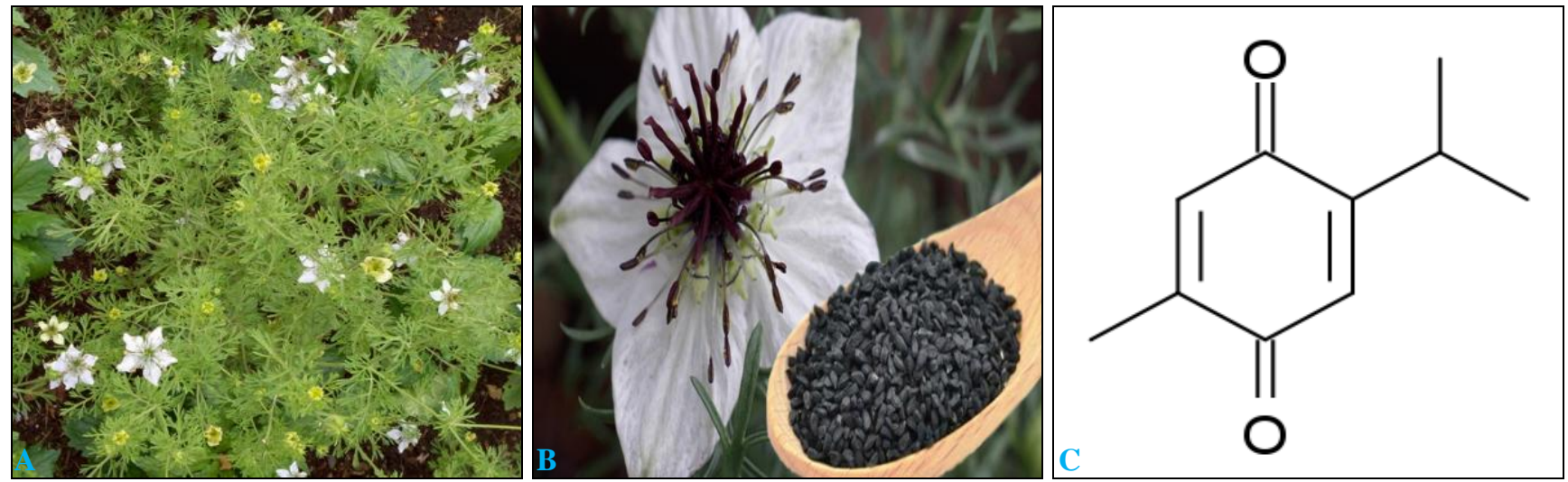

FIG. 1: (A) NIGELLA SATIVA PLANT (B) ITS FLOWER AND SEEDS (C) CHEMICAL STRUCTURE OF ACTIVE COMPOUND OF SEEDS, THYMOQUINONE

TABLE 1: THE RELEVANT PROPERTIES OF THYMOQUINONE

\begin{tabular}{cc} 
IUPAC Name & 2-isopropyl-5-methyl benzo-1, 4- \\
& quinone \\
Molecular formula & $\mathrm{C}_{10} \mathrm{H}_{12} \mathrm{O}_{2}$ \\
Molar Mass & $164.20 \mathrm{~g} \mathrm{~mol}^{-1}$ \\
Appearance & Crystalline and dark yellow \\
CAS number & $490-91-5$ \\
Pub Chem CID & 10281 \\
\hline
\end{tabular}

Structurally, it is as similar to coenzyme Q, which is an important antioxidant of the electron transport system ${ }^{13}$. By oxidation of THY with $\mathrm{H}_{2} \mathrm{O}_{2}$, TQ can be readily synthesized in gram amounts ${ }^{14}$. Moreover, according to one hypothesis based on chemical composition, the controlled heating causes oxidation of THY and converts it into THQ. The heating process leads to a further oxidative process that converts THQ into TQ, resulting in the accumulation of larger amounts of TQ.

Based on the presence of light, the photoisomerization of TQ may cause an accumulation of its dimer, DTQ ${ }^{13}$. Besides this, during quinone separation and extraction from seeds, TQ photodimerization as a consequence of exposure to sunlight produces DTQ ${ }^{15}$. Conversions of different quinones by the chemical reaction are shown in Fig. 2.
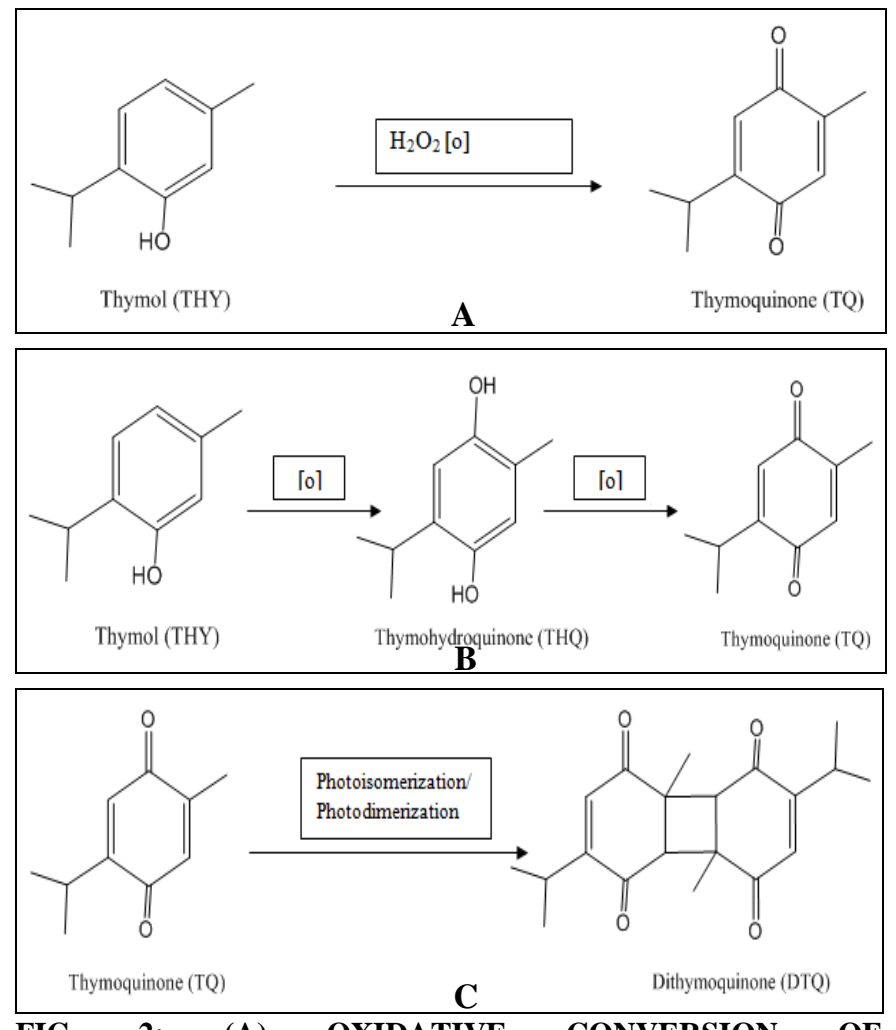

FIG. 2: (A) OXIDATIVE CONVERSION OF THYMOQUINONE FROM THYMOL. (B) HYPOTHESIZED MECHANISM OF TRANSITION BETWEEN QUINONES BY OXIDATION UNDER CONTROLLED HEAT. (C) CONVERSION OF DITHYMOQUINONE FROM THYMOQUINONE BY PHOTOISOMERIZATION OR PHOTODIMERIZATION REACTIONS 
Pharmacological Potential of Thymol: Numerous in-vitro and in-vivo studies have been done to investigate the pharmacological potential of thymol.

Anti-Inflammatory Effects: Inflammation is one of the main causes of many diseases. Infection and oxidative stress activate the expression of inflammatory genes, which promoted a cascade of inflammatory mediators, including cytokines, eicosanoids, oxidants, and lytic enzymes. Therefore, the introduction of a preventive agent is promising for the treatment of inflammatory disorders. A number of studies showed TQ could suppress inflammatory mediators and oxidative stress markers ${ }^{16}$. Treatment with TQ inhibited the synthesis of 5-lipoxygenase and 5hydroxyeicosatetraenoic acid production in calcium or ionophore-stimulated polymorphonuclear leukocytes in rats ${ }^{17}$. TQ inhibited eicosanoid generation by inhibiting 5-lipoxygenase and leukotriene $\mathrm{C} 4$ synthase in human blood cells ${ }^{18}$. TQ in the concentration of $0.16-16.4 \mathrm{mg} / \mathrm{ml}$ was effective for the inhibition of eicosanoid generation in human blood cells. It has been proved that TQ acts as a potent anti-inflammatory agent ${ }^{19}$. TQ exhibited a greater inhibitory effect in inflammatory cells of bronchoalveolar lavage (BAL) fluid and lung tissues. TQ also inhibited the expression of transforming growth factor$\beta 1$ andmRNA levels of inducible nitric oxide synthase. These results suggested that TQ is more potent anti-inflammatory agents against asthma ${ }^{19}$.
The anti-inflammatory effect of TQ was observed in allergic encephalomyelitis. TQ $(1 \mathrm{mg} / \mathrm{kg}$, injected into the tail vein) increased the levels of glutathione and reduced perivascular inflammation and encephalomyelitis symptoms in rats ${ }^{20}$. TQ $(15 \mathrm{mg} / \mathrm{kg})$ treatment showed 90 percent preventive and 50 percent curative effects in chronic relapsing multiple sclerosis ${ }^{21}$.

Anti-Tumor Effects: There are many studies are available which support the antitumor effect of TQ in both in-vitro and in-vivo studies ${ }^{22}$. The inhibitory effect of TQ (10-200 $\mu \mathrm{M})$ was shown on the growth of colon cancer cell. The apoptotic effects of TQ could be modulated by Bcl-2protein by an increase in the mRNA expression of $\mathrm{p} 53{ }^{23}$. Also, TQ in the dose of 20,40 and $80 \mu \mathrm{mol} / \mathrm{l}$ showed anti-tumor and anti-angiogenic effects in the human osteosarcoma cell line (SaOS-2) through suppressing NF- $\mathrm{KB}$, its regulated molecules and blocking the human umbilical vein endothelial cell tube formation ${ }^{24}$. TQ is an anti-neoplastic drug that decreased cell survival in a dose-dependent manner. This effect was more significantly in p53null MG63 cells (IC $(50)=17 \mu \mathrm{M})$ than in p53mutant MNNG/HOS cell $\left(\mathrm{IC}_{50}=38 \mu \mathrm{M}\right)^{25}$.

Moreover, TQ $\left(\mathrm{IC}_{50}=10.67 \pm 0.12\right.$ and $9.33 \pm 0.19$ $\mu \mathrm{g} / \mathrm{ml})$ exhibited cytotoxic effects in several cancer cell lines. TQ was more potent than cisplatin in eliminating cervical squamous carcinoma $(\mathrm{SiHa})$ cells via apoptosis with down-regulation of Bcl-2 $\operatorname{protein}^{26}$.

\section{TABLE 2: ANTI-TUMOR EFFECT OF THYMOQUINONE}

\begin{tabular}{|c|c|c|c|}
\hline Compound & Study Models & Effects & References \\
\hline Thymoquinone & $\begin{array}{l}\text { HCT-116 human colon } \\
\text { cancer cells }\end{array}$ & $\begin{array}{c}\text { Apoptotic effects of TQ on HCT-116 (by } \uparrow \mathrm{Bcl}-2 \\
\text { protein and mRNA expression of p53) }\end{array}$ & 23 \\
\hline Thymoquinone & $\begin{array}{l}\text { Human osteosarcoma cell } \\
\text { line (SaOS-2) }\end{array}$ & $\begin{array}{l}\text { Apoptotic effect ( } \downarrow \text { tumor angiogenesis and tumor } \\
\text { growth through suppressing NF- } \mathrm{kB} \text { ) }\end{array}$ & 24 \\
\hline Thymoquinone & $\begin{array}{l}\text { Human umbilical vein } \\
\text { endothelial cell }\end{array}$ & $\begin{array}{l}\text { Apoptotic effect ( } \downarrow \text { tumor angiogenesis and tumor } \\
\text { growth through suppressing NF- } \mathrm{kB} \text { ) }\end{array}$ & 24 \\
\hline Thymoquinone & $\begin{array}{l}\text { Human osteosarcoma cell } \\
\text { lines }\end{array}$ & $\begin{array}{c}\text { p53-independent apoptosis in human osteosarcoma } \\
\text { cells }\end{array}$ & 25 \\
\hline Thymoquinone & $\begin{array}{l}\text { Human cervical squamous } \\
\text { carcinoma cells }\end{array}$ & $\begin{array}{l}\text { Cytotoxic effect (elevation of p53 and } \\
\text { downregulation of the anti-apoptotic Bcl-2 protein) }\end{array}$ & 26 \\
\hline
\end{tabular}

Anti-Microbial Effects: The anti-bacterial activity of TQ and its biofilm inhibitory effect on 11 human pathogenic microscopic organisms were explored. TQ $(0-512 \mu \mathrm{g} / \mathrm{ml})$ demonstrated a noteworthy enemy of the bacterial movement against the vast majority of the microscopic organisms tested (MIC values ranged from 8-32 $\mu \mathrm{g} / \mathrm{ml})$, particularly Grampositive microorganisms (Staphylococcus epidermidis CIP and 106510 Staphylococcus aureus ATCC 25923). The cell oxidative movement was affected by TQ, which avoided cell attachment to the surface of the glass slide ${ }^{27}$. 
Effects on Metabolic Disorders: Several studies have been exhibited anti-hyperlipidemic and antidiabetic activities of TQ and its effect on other metabolic disorders. Several possible mechanisms have been proposed for justifying these effects. It was demonstrated that TQ might reduce the expression of gluconeogenic enzymes viz., glucose6-phosphatase, fructose 1, 6 bi-phosphatase and hepatic glucose production ${ }^{28,29}$. TQ could enhance the uptake of low-density lipoprotein-cholesterol (LDL-C) by upregulation of LDL-C hepatic receptors ${ }^{30}$.

Anti-Diabetic Effects: Diabetes is a metabolic disorder that consists of elevation in serum glucose levels and develops a deficiency, sensitivity or both of insulin caused by destruction or inactivity of $\beta$ cells. Diabetes is usually associated with several chronic complications such as cardiovascular diseases, neuropathy and nephropathy 31,32 . Scientific validation of traditional medicinal plant remedies for diabetes may lead to the development of alternative drugs. More than 1200 plant species reported having been used to treat diabetes and its related complications, including Nigella sativa ${ }^{33}$. The anti-diabetic effect of TQ has been shown in the STZ-induced diabetic rats. TQ reduced the activation of the COX-2 enzyme in the pancreatic $\beta$-cells. Supplementation of diabetic rats with TQ also decreased the MDA levels and increased the Superoxide Dismutase (SOD) levels in the pancreatic tissue ${ }^{34}$. It was also showed that treatment with TQ (20 mg/kg body weight) of diabetic mice during pregnancy and lactation periods protected their offspring from diabetes and its related complications via decreasing blood glucose levels, plasma pro-inflammatory cytokines (IL-1 $\beta$, IL-6 and TNF-a), free radicals, lipids and restoring the number of circulating lymphocytes, Tcell proliferation and aberrant AKT phosphorylation ${ }^{35}$.

TQ (50 mg/kg, body weight) reduced blood glucose levels in diabetic hamster during pregnancy by inhibiting the synthesis of gluconeogenic enzymes 36. In another study, TQ ( $80 \mathrm{mg} / \mathrm{kg}$, body weight) decreased plasma glucose levels and increased insulin levels by enhancing glucose utilization and decreasing hepatic glucose production. TQ has been shown to suppress the activity of glucose-6phosphatase and fructose-1, 6-bisphosphatase enzymes ${ }^{37}$. TQ ameliorated the increased levels of lipid peroxidation and decreased the level of vitamin $\mathrm{C}$, vitamin $\mathrm{E}$, catalase, glutathione-Stransferase, glutathione peroxidase, and reduced glutathione content. These findings exhibited that TQ has the ameliorating effects on $\beta$-cell action via its antioxidant potential ${ }^{37}$.

Gastro-Protective Effects: Ample evidence exists for supporting the protective effect of TQ on gastrointestinal tract. TQ showed a protecting effect against gastric lesions, which may be due to its potent anti-oxidant property. TQ corrected ischemia/ reperfusion (I/R)-induced gastric dysfunction and stomach ulcer in rats. It increased the levels of glutathione and superoxide dismutase activity and reduced malonaldehyde levels and myeloperoxidase activity ${ }^{38}$. TQ possessed protecting action against liver enzyme leakage and lipid peroxidation. It showed anti-oxidant, membrane stabilizing and free radical scavenging action 39,40 . The gastroprotective mechanisms of TQ resulted from inhibiting acid secretion, proton pump $\left(\mathrm{H}^{+} / \mathrm{K}^{+}\right.$-ATPase $)$, neutrophil infiltration, through enhancing mucin secretion and nitric oxide (NO) production ${ }^{41}$. Pretreatment with TQ (10 $\mathrm{mg} / \mathrm{kg}$ body weight for 3 days) in rats was able to give complete protection against acetic acidinduced colitis, however, thymoquinone in a dose of $5 \mathrm{mg} / \mathrm{kg}$ body weight produced partial protection. These results showed a protective effect of thymoquinone against experimentally-induced colitis which may be partly due to an antioxidant action ${ }^{42}$. The anti-histaminic effect is an essential defensive mechanism against gastric injury ${ }^{43}$ and TQ showed potent anti-histaminic effect ${ }^{42}$. Altogether, these studies confirm the gastroprotective effect of TQ in an animal model which makes it possible to use as a natural drug against gastrointestinal defects in human.

Cardio-Protective Effect: Cardiovascular diseases are increasing rapidly worldwide. The alteration in lipid profiles, diabetes and hypertension, are the major risk factors for the development of cardiovascular diseases ${ }^{44}$. Atherosclerosis is the main cause of coronary artery disease identified by a complex process of thickening and narrowing of the arterial walls caused by the accumulation of lipids, primarily oxidized cholesterol, in the intimal or inner layer in combination with connective 
tissue and calcification creating an atheromatous (fibrofatty) plaque ${ }^{45}$. Atherosclerotic plaque is composed of lipids, cholesterol, oxidized-low density lipoprotein (Ox-LDL), calcium and fibrin that cause hardening and narrowing of the arteries 45. Hypercholesterolemia is the main cause of the initiation and progress of atherosclerosis 46 . Inflammatory cells such as vascular endothelial cells and polymorphonuclear leukocytes are activated in hypercholesterolemia and cause increased production of free radicals ${ }^{47}$. Several studies have been shown that natural antioxidant components such as TQ ameliorated oxidative stress-induced atherosclerosis ${ }^{48}$. Other studies also observed that TQ $(20 \mathrm{mg} / \mathrm{kg}$ body weight $)$ decreased the oxidative stress markers, lipid profiles and prevented the progression of plaque formation in hypercholesterolemic animals ${ }^{49}$.

Hepato-Protective Effect: In recent years, consideration has been attracted to various plants and plant-derived compounds for the treatment of liver infirmities. The defensive impact of TQ on liver injuries has been demonstrated by a few investigations. TQ could neutralize the negative impact of different harming agents on liver tissues. TQ has been shown to prevent non-enzymatic lipid peroxidation in liver homogenates and showed the protective action against $\mathrm{CCl}_{4}$-induced toxicity through its anti-oxidant potential. Oral administration of TQ (100 mg/kg body weight), gave considerable protection against the treatment of carbon tetrachloride $\left(\mathrm{CCl}_{4}\right)$ hepatotoxicity ${ }^{50}$. TQ showed hepatoprotective activity against tert-butyl hydroperoxide (TBHP)- induced toxicity in isolated rat hepatocytes. It prevented the reduction of intracellular glutathione and maintained the integrity of the cell membrane, as well as decreasing the leakage of the alanine transaminase (ALT) and aspartic transaminase (AST). This protective role of TQ is comparable to the silybin, hepato-protective agent possessing anti-oxidant properties $^{39}$.

TQ supplementation efficiently reduced acetaminophen-induced oxidative stress, nitric oxide production and improved mitochondrial energy production ${ }^{51}$. TQ protected liver injury through various mechanisms, including inhibition of lipid peroxidation, increase in total thiol content and reduced glutathione level, radical scavenging, increasing the activity of quinine reductase, superoxide dismutase, catalase and glutathione transferase and inhibition of NF- $\kappa \mathrm{B}$ activity ${ }^{50}$.

Toxicological Studies: Increased interest in phytomedicine, brings health issues of safety and legal requirements. Numerous examinations were done to evaluate the toxicological properties of TQ in-vitro and in-vivo ${ }^{52,53}$ and just a set number of reports on the possible harmful impacts of TQ exist. In the pathological conditions where TQ has been appeared to be a most promising prophylactic agent, it additionally has been appeared to be enriched with a moderately low harmfulness $54,55$. TQ is a very well tolerated drug in mice. It has been shown that TQ administered for 20 consecutive days has not induced death in Balbo/C rats or has not affected the average body weight, which is a very sensitive parameter for toxicity in the rodent ${ }^{56}$. Neurological function of TQ was not associated with any therapeutic changes in laboratory variables. TQ administered in the dose of $1 \mathrm{mg} / \mathrm{kg}$ body weight /day was mostly well tolerated 57 . There was no sign of toxicity except for the reduction in the amount of plasma glucose concentration in addition to TQ at concentrations up to $0.03 \%$ for 3 months in drinking water of rats 58 . The steady delivery of TQ for 30 days using TriCalcium Phosphate Lysine with 0.02 grams of TQ for adult male rats, showed very little or no side effect on reproductive organs 59 .

CONCLUSION: In recent years, the focus on traditional uses of natural products, received much attention as they are believed to be safe for human use. They deserve scrutiny for phytochemical investigation, biological evaluation on experimental animal models, toxicity studies and investigation of the molecular mechanism of actions. This review enumerates the biological properties of TQ and reveals its therapeutic potential against many diseases including diabetes, cancer, cardiac, liver illnesses, and gastrointestinal defects. Available data are indicators of its use as a nutraceutical or prophylactic or adjuvant for longlasting chronic oxidative stress and long-lasting diseases associated with inflammation. Molecular pharmacological data from many studies show that TQ modulates apoptotic, enzymatic, and cell signaling pathways, transcription factors, different receptors, and ion channels, modify to meet their 
pharmacological effects. TQ acts as antidiabetic agent and improved hyperlipidemia through increasing antioxidant and decreasing lipid peroxidation. TQ showed protective properties against a cardiovascular disease which may be related to its anti-inflammatory and antioxidant activities. The present review reveals on all the aspects of the herbal compound and throws the attention to set the mind of the researchers to carry out the work for developing its various formulations, which can ultimately be beneficial for the human as well as animals. However, further research at the clinical and pre-clinical levels is necessary to determine the therapeutic potential of TQ in various diseases.

\section{ACKNOWLEDGEMENT: Swati Agarwal} acknowledges the Junior Research Fellowship (JRF) from University Grants Commission (UGC), New Delhi, India.

\section{CONFLICT OF INTEREST: The authors} declared no conflict of interest.

\section{REFERENCES:}

1. Gray JP, Zayasbazan BD, Yuan T, Seeram N, Rebar R, Follmer $\mathrm{R}$ and Heart EA: Thymoquinone, a bioactive component of Nigella sativa, normalizes insulin secretion from pancreatic $\beta$-cells under glucose overload via regulation of malonyl-CoA. American Journal of Physiology-Endocrinology and Metabolism 2015; 310(6): E394-E404.

2. Mathur ML, Gaur J, Sharma $\mathrm{R}$ and Haldiya KR: Antidiabetic properties of a spice plant Nigella sativa. Journal of Endocrinology and Metabolism 2011; 1(1): 1-8.

3. Hajhashemi V, Ghannadi A and Jafarabadi H: Black cumin seed essential oil, as a potent analgesic and antiinflammatory drug. Phytotherapy Research: An International Journal Devoted to Pharmacological and Toxicological Evaluation of Natural Product Derivatives 2004; 18(3): 195-99.

4. Fararh KM, Atoji Y, Shimizu Y and Takewaki T: Insulinotropic properties of Nigella sativa oil in Streptozotocin plus Nicotinamide diabetic hamster. Research in Veterinary Science 2002; 73(3): 279-82.

5. Khan MAU, Ashfaq MK, Zuberi HS, Mahmood MS and Gilani AH: The in-vivo antifungal activity of the aqueous extract from Nigella sativa seeds. Phytotherapy Research: An International Journal Devoted to Pharmacological and Toxicological Evaluation of Natural Product Derivatives 2003; 17(2): 183-86.

6. Sultan MT, Butt MS, Anjum FM, Jamil A, Akhtar S and Nasir M: Nutritional profile of indigenous cultivar of black cumin seeds and antioxidant potential of its fixed and essential oil. Pakistan Journal of Botany 2009; 41(3): 1321-30.

7. Taborsky J, Kunt M, Kloucek P, Lachmaz J, Zeleny V and Kokoska L: Identification of potential sources of thymoquinone and related compounds in Asteraceae,
Cupressaceae, Lamiaceae, and Ranunculaceae families. Open Chemistry 2012; 10(6): 1899-06.

8. Havlik J, Kokoska L, Vasickova $\mathrm{S}$ and Valterova I: Chemical composition of essential oil from the seeds of Nigella arvensis L. and assessment of its antimicrobial activity. Flavour and Fragrance Journal 2006; 21(4): 71317.

9. El-Dakhakhny M: Studies on the chemical constitution of Egyptian Nigella sativa L. Seeds. PlantaMedica 1963; 11(04): 465-70.

10. Ecevit H, Gunduz K, Bilgic N, Izmirli M and Gogebakan B: The effect of thymoquinone on BEAS-2B cell viability and TGF- $\beta 1$ release. Advances in Modern Oncology Research 2017; 3(1): 15-19.

11. Trippier PC: Selecting good 'drug-like' properties to optimize small molecule blood-brain barrier penetration. Current medicinal chemistry 2016; 23(14): 1392-07.

12. Darakhshan $\mathrm{S}$, Pour $\mathrm{AB}$, Colagar $\mathrm{AH}$ and Sisakhtnezhad S: Thymoquinone and its therapeutic potentials. Pharmacological Research 2015; 95: 138-58.

13. Mabrouk A and Cheikh HB: Thymoquinone ameliorates lead-induced suppression of the antioxidant system in rat kidneys. Libyan Journal of Medicine 2016; 11(1): 31018.

14. Jakaria M, Cho DY, Haque E, Karthivashan G, Kim IS, Ganesan P and Choi DK: Neuropharmacological Potential and Delivery Prospects of Thymoquinone for Neurological Disorders. Oxidative medicine and cellular longevity 2018; 1209801.

15. Amin B and Hosseinzadeh H: Black cumin (Nigella sativa) and its active constituent, thymoquinone: an overview on the analgesic and anti-inflammatory effects. Planta Medica 2016; 82(01/02): 8-16.

16. Salem ML: Immunomodulatory and therapeutic properties of the Nigella sativa L. seed. International Immune Pharmacology 2005; 5(13-14): 1749-70.

17. El-Dakhakhny M, Madi NJ, Lembert $\mathrm{N}$ and Ammon HPT: Nigella sativa oil, nigellone and derived thymoquinone inhibit synthesis of 5-lipoxygenase products in polymorphonuclear leukocytes from rats. Journal of Ethnopharmacology 2002; 81(2): 161-64.

18. Mansour $M$ and Tornhamre $S$ : Inhibition of 5lipoxygenase and leukotriene $\mathrm{C} 4$ synthase in human blood cells by thymoquinone. Journal of Enzyme Inhibition and Medicinal Chemistry 2004; 19(5): 431-36.

19. Ammar ESM, Gameil NM, Shawky NM and Nader MA: Comparative evaluation of anti-inflammatory properties of thymoquinone and curcumin using an asthmatic murine model. International Immune Pharmacology 2011; 11(12): 2232-36.

20. Mohamed A, Shoker A, Bendjelloul F, Mare A, Alzrigh $\mathrm{M}$, Benghuzzi $\mathrm{H}$ and Desin $\mathrm{T}$ : Improvement of experimental allergic encephalomyelitis (EAE) by thymoquinone; an oxidative stress inhibitor. Biomedical Sciences Instrumentation 2003; 39: 440-45.

21. Mohamed A, Waris HM, Ramadan H, Quereshi M and Kalra J: Amelioration of chronic relapsing experimental autoimmune encephalomyelitis (cr-eae) using thymoquinone-biomed 2009. Biomedical sciences instrumentation 2009; 45: 274-279.

22. Woo CC, Kumar AP, Sethi $G$ and Tan KHB: Thymoquinone: a potential cure for inflammatory disorders and cancer. Biochemical pharmacology 2012; 83(4): 443-51

23. Gali-Muhtasib H, Diab-Assaf M, Boltze C, Al-Hmaira J, Hartig R, Roessner A and Schneider-Stock R: Thymoquinone extracted from black seed triggers apoptotic cell death in human colorectal cancer cells via a 
p53-dependent mechanism. International Journal of Oncology 2004; 25(4): 857-66.

24. Peng L, Liu A, Shen Y, Xu HZ, Yang SZ, Ying XZ, Liao W, Liu HX, Lin ZQ, Chen Q Y, Cheng SW and Shen WD: Antitumor and anti-angiogenesis effects of thymoquinone on osteosarcoma through the NF- $\mathrm{kB}$ pathway. Oncology reports 2013; 29(2): 571-78.

25. Roepke M, Diestel A, Bajbouj K, Walluscheck D, Schonfeld P, Roessner A, Schneider-Stock R and GaliMuhtasib H: Lack of p53 augments thymoquinone-induced apoptosis and caspase activation in human osteosarcoma cells. Cancer biology and therapy 2007; 6(2): 160-69.

26. $\mathrm{Ng} \mathrm{WK}$, Yazan LS and Ismail M: Thymoquinone from Nigella sativa was more potent than cisplatin in eliminating of $\mathrm{SiHa}$ cells via apoptosis with downregulation of $\mathrm{Bcl}-2$ protein. Toxicology in-vitro 2011; 25(7): 1392-98.

27. Chaieb K, Kouidhi B, Jrah H, Mahdouani K and Bakhrouf A: Antibacterial activity of Thymoquinone, an active principle of Nigella sativa and its potency to prevent bacterial biofilm formation. BMC Complementary and Alternative Medicine 2011; 11(1): 29.

28. Al-Rasheed N, Al-Rasheed N, Bassiouni Y, Faddah L and Mohamad AM: Potential protective effects of Nigella sativa and Allium sativum against fructose-induced metabolic syndrome in rats. Journal of Oleo Science 2014; 63(8): 839-48.

29. Alimohammadi S, Hobbenaghi R, Javanbakht J, Kheradmand D, Mortezaee R, Tavakoli M, Khadivar F and Akbari H: RETRACTED ARTICLE: Protective and antidiabetic effects of extract from Nigella sativa on blood glucose concentrations against streptozotocin (STZ)induced diabetic in rats: an experimental study with histopathological evaluation. Diagnostic Pathology 2013; 8(1): 137.

30. Ibrahim RM, Hamdan NS, Mahmud R, Imam MU, Saini SM, Rashid SNA, Abd Ghafar SA, Latiff LA and Ismail M: A randomised controlled trial on hypolipidemic effects of Nigella Sativa seeds powder in menopausal women. Journal of Translational Medicine 2014; 12(1): 82.

31. Umeno A, Horie $M$, Murotomi $K$, Nakajima $Y$ and Yoshida Y: Antioxidative and antidiabetic effects of natural polyphenols and isoflavones. Molecules 2016; 21(6): 708.

32. Adewoye EO and Adele BO: Effect of methanol extract of Musa sapientum leaves on protein glycation and e1ythrocyte antioxidant status in alloxan-induced diabetic Wistar rats. African Journal of Medicine and Medical Sciences 2015; 44(3): 261-68.

33. Farkhondeh T, SamarghandianS and Borji A: An overview on cardioprotective and anti-diabetic effects of thymoquinone. Asian Pacific Journal of Tropical Medicine 2017; 10(9): 849-54.

34. Al-Wafai RJ: Nigella sativa and thymoquinone suppress cyclooxygenase- 2 and oxidative stress in pancreatic tissue of streptozotocin-induced diabetic rats. Pancreas 2013; 42(5): 841-49.

35. Badr G, Mahmoud MH, Farhat K, Waly H, AI-Abdin OZ and Rabah OM: Maternal supplementation of diabetic mice with thymoquinone protects their offspring from abnormal obesity and diabetes by modulating their lipid profile and free radical production and restoring lymphocyte proliferation via PI3K/AKT signaling. Lipids in Health and Disease 2013; 12: 37.

36. Fararh KM, Shimizu Y, Shiina T, Nikami H, Ghanem MM and Takewaki T: Thymoquinone reduces hepatic glucose production in diabetic hamsters. Research in Veterinary Science 2005; 79(3): 219-23.

37. Sankaranarayanan $\mathrm{C}$ and Pari L: Thymoquinone ameliorates chemical induced oxidative stress and b-cell damage in experimental hyperglycemic rats. ChemicoBiological Interactions 2011; 190(2-3): 148-54.

38. El-Abhar HS, Abdallah DM and Saleh S: Gastroprotective activity of Nigella sativa oil and its constituent, thymoquinone, against gastric mucosal injury induced by ischaemia/reperfusion in rats. Journal of Ethnopharmacology 2003; 84(2-3): 251-58.

39. Gholamnezhad Z, Havakhah S and Boskabady MH: Preclinical and clinical effects of Nigella sativa and its constituent, thymoquinone: A review. Journal of Ethnopharmacology 2016; 190: 372-86.

40. Lebda FM, Ahmed MA, Abd ESA and Shawky MK: Protective effect of thymoquinone against d-galactosamine-induced liver injury in rats. Australian Journal of Basic and Applied Sciences 2011; 5(2): 49-58.

41. Magdy MA, Hanan EA and Nabila EM: Thymoquinone: Novel gastroprotective mechanisms. European Journal of Pharmacology 2012; 697(1-3): 126-31.

42. Mahgoub AA: Thymoquinone protects against experimental colitis in rats. Toxicology letters 2003; 143(2): 133-43.

43. Kahraman A, Erkasap N, Köken T, Serteser M, Aktepe F and Erkasap: The antioxidative and antihistaminic properties of quercetin in ethanol-induced gastric lesions. Toxicology 2003; 183 (1-3): 133-42.

44. Yusuf S, Reddy S, Ounpuu S and Anand S: Global burden of cardiovascular diseases part I: general considerations, the epidemiologic transition, risk factors, and impact of urbanization. Circulation 2001; 104(22): 2746-53.

45. Ahmadi A, Stone GW, Leipsic J, Shaw U, Villines TC, Kern MJ, Hecht H, Erlinge D, Ben-Yehuda O, Maehara A and Arbustini E: Prognostic determinants of coronary atherosclerosis in stable ischemic heart disease: anatomy, physiology, or morphology? Circulation Research 2016; 119(2): 317-29.

46. Al-Naqeep G, Al-Zubairi AS, Ismail M, Amom ZH and Esa NM: Antiatherogenic potential of Nigella sativa seeds and oil in diet-induced hypercholesterolemia in rabbits. Evidence-Based Complementary and Alternative Medicine 2011; 2011: 213628.

47. Liu H, Liu HY, Jiang YN and Li N: Protective effect of thymoquinone improves cardiovascular function, and attenuates oxidative stress, inflammation and apoptosis by mediating the PI3K/Akt pathway in diabetic rats. Molecular medicine reports 2016; 13(3): 2836-42.

48. El-Agamy OS and Nader MA: Attenuation of oxidative stress-induced vascular endothelial dysfunction by thymoquinone. Experimental biology and medicine, (Maywood) 2012; 237(9): 1032-38.

49. Ragheb A, Elbarbry F, Prasad K, Mohamed A, Ahmed MS and Shoker A: Attenuation of the development of hypercholesterolemic atherosclerosis by thymoquinone. The International journal of angiology: official publication of the International College of Angiology, Inc 2008; 17(4): 186-92.

50. Tabassum H, Ahmad A and Ahmad IZ: Nigella sativa L. and its bioactive constituents as hepatoprotectant: a review. Current Pharmaceutical Biotechnology 2018; 19: 43-67.

51. Nagi MN, Almakki HA, Sayed-Ahmed MM and AlBekairi AM: Thymoquinone supplementation reverses acetaminophen-induced oxidative stress, nitric oxide 
production and energy decline in mice liver. Food and Chemical Toxicology 2010; 48(8-9): 2361-65.

52. Abukhader MM: The effect of route of administration in thymoquinone toxicity in male and female rats. Indian Journal of Pharmaceutical Sciences 2012; 74(3): 195.

53. Bai T, Lian LH, Wu YL, WanY and Nan JX: Thymoquinone attenuates liver fibrosis via PI3K and TLR4 signaling pathways in activated hepatic stellate cells. International Immunopharmacology 2013; 15(2): 275-81.

54. Zafeer MF, Waseem M, Chaudhary S and Parvez S: Cadmium-induced hepatotoxicity and its abrogation by thymoquinone. Journal of Biochemical and Molecular Toxicology 2012; 26(5): 199-05.

55. Mansour MA, Ginawi OT, El-HadiyahT, El-Khatib AS, Al-Shabanah OA and Al-Sawaf HA: Effects of volatile oil constituents of Nigella sativa on carbon tetrachlorideinduced hepatotoxicity in mice: evidence for antioxidant effects of thymoquinone. Research Communications in Mol Pathology and Pharmacology 2001; 110(3-4): 239-52.
56. Gali-Muhtasib H, Ocker M, Kuester D, Krueger S, El-Hajj Z, Diestel A, Evert M, El-Najjar N, Peters B, Jurjus A and Roessner A: Thymoquinone reduces mouse colon tumor cell invasion and inhibits tumor growth in murine colon cancer models. Journal of Cellular and Molecular Medicine 2008; 12(1): 330-42.

57. Akhondian J, Kianifar H, Raoofziaee M, Moayedpour A, Toosi MB and Khajedaluee M: The effect of thymoquinone on intractable pediatric seizures (pilot study). Epilepsy Research 2011; 93(1): 39-43.

58. Goyal SN, Prajapati CP, Gore PR, Patil CR, Mahajan UB, Sharma C, Talla SP and Ojha SK: Therapeutic potential and pharmaceutical development of thymoquinone: a multitargeted molecule of natural origin. Frontiers in Pharmacology 2017; 8: 656.

59. Kirui PK, Cameron J, Benghuzzi HA, Tucci M, Patel R, Adah F and Russell G: Effects of sustained delivery of thymoqiunone on bone healing of male rats. Biomedical Sciences Instrumentation 2004; 40: 111-16.

\section{How to cite this article:}

Agarwal S, Srivastava R and Mishra N: An overview of therapeutic potential of thymoquinone. Int J Pharm Sci \& Res 2019; 10(8): 353239. doi: 10.13040/IJPSR.0975-8232.10(8).3532-39.

All ๑ 2013 are reserved by International Journal of Pharmaceutical Sciences and Research. This Journal licensed under a Creative Commons Attribution-NonCommercial-ShareAlike 3.0 Unported License.

This article can be downloaded to Android OS based mobile. Scan QR Code using Code/Bar Scanner from your mobile. (Scanners are available on Google Play store) 